\title{
Power Density Measurement within Kaduna North Area of Kaduna State, Nigeria
}

\author{
Bello I Ayodeji ${ }^{1}$, Nicodemus Kure ${ }^{2, *}$, Isaac H Daniel ${ }^{2}$, Emmanuel J Adoyi ${ }^{2,3}$, Esther $\mathbf{N}$ \\ Obiechile $^{2,3}$ and Fidelis Yunusa ${ }^{2,4}$ \\ ${ }^{1}$ Division of Agricultural Colleges, Ahmadu Bello University, Zaria, Nigeria. \\ ${ }^{2}$ Department of Physics, Kaduna State University, Kaduna, Nigeria. \\ ${ }^{3}$ Department of Physics, Nigerian Defence Academy, Kaduna, Nigeria. \\ ${ }^{4}$ Scientific Equipment Development Institute, Minna, Nigeria. \\ Corresponding E-mail: kurenicodemus@gmail.com
}

Received 29-07-2021

Accepted for publication 09-10-2021

Published 20-10-2021

\begin{abstract}
The measurement of possible presence of radiofrequency (RF) radiations from telecommunication base stations was carried out within Kaduna North Area of Kaduna State, to estimate the maximum level of power density from RF radiations to which the member of the populace within specific radius from the base transceiver station (BTS) are exposed to in relation to the existing guidelines to human exposure. Power density $\mathrm{S}\left(\mu \mathrm{Wm}^{-2}\right)$ measurements were made at interval of $20 \mathrm{~m}$ to check the exposure level at public locations from $10 \mathrm{RF}$ antenna sites starting from the foot of each BS to distance (radius) of $100 \mathrm{~m}$ using Aaronia Spectran HF-4060 Analyser and the electric field strength E ( $\left.\mathrm{Vm}^{-1}\right)$ were calculated. The highest and lowest value obtained from measured mean power densities were $108.27 \mu \mathrm{Wm}^{-2}$ and $94.74 \mu \mathrm{Wm}^{-2}$ from a distance of $100 \mathrm{~m}$ and 40 $\mathrm{m}$ respectively. Also, the highest and lowest average electric field strength were $202.03\left(\mathrm{Vm}^{-1}\right)$ and $188.99\left(\mathrm{Vm}^{-1}\right)$ at $100 \mathrm{~m}$ and $40 \mathrm{~m}$ respectively. The result obtained, indicates that the measured values were far less than the permissible exposure limits for both workers and the general public as set by the International Commission on Non-ionizing Radiation Protection (ICNIRP). These results shows that the exposure levels in these areas are low and as such will not pose significant health risks to the people living in the study area.
\end{abstract}

Keywords: Telecommunication; Exposure; Power Density; Base Transceiver Station and Kaduna North

\section{INTRODUCTION}

$\mathrm{T}$ elecommunication devices have become an integral part of our life; providing services that range from phone calls, Bluetooth connections, internet connections and information sharing via online media [1]. The telecommunication sector is a very important sector of the Nigerian economy. Communication to an economy is important and cannot be overemphasized. Specifically, telecommunication sector is central to the development process of a healthy economy and societal growth. Telecommunication is the primary means of transmitting information, resulting to installation of telecommunication mast around residential and office areas which may have negative impacts on the life of people living around such vicinity [2]. Telecommunication mast has been studied differently which has received comparatively little attention. Telecommunication Base Transceiver stations (BTSs) are generally designed to enhance communication via RF network signals for digital telecommunication users both in urban and rural communities [2]. The typical BTS consists of telecommunication mast upon which radio frequency transmitters and receivers are mounted, powered by digital electronic boasters which are installed in shelters within the BTS site. Several environmental issues have appeared due to introduction of this technology, which includes the indiscriminate siting and erection of BTS all over Nigeria. The Global System for Mobile (GSM) service first became 
available in Nigeria in the year 2001 in Lagos and Abuja. By mid-2002 there were approximately 2.27 million subscribers throughout Nigeria and has since rose to over 143.05 million [3]. BTS capacity is a major issue that the telecommunication companies are faced with at present [4]. As the population continues to grow and so does the number of subscribers using GSM services, and more BTSs are required to meet subscribers demand for reliable coverage, many of such BSs are sited within residential, commercial, industrial and transit routes. Reference [5] reported that the location of adequate telecommunication masts and residents living in Oshogbo, Nigeria are susceptible to physical, health and environmental problems at certain distances from mast. Furthermore, using a descriptive cross-sectional survey, the health hazards of non-ionizing radiation from telecommunication mast on the exposed community within Kaduna and Lagos metropolis were assessed and presented in [2] and [6]. The instrument mostly used by researchers in monitoring high frequency radiations includes: RF EMR Strength Meter [2] and Radiation Monitor Radex [7]. The study was carried out using Aaronia Spectran HF-4060 Analyser to determine the power density of selected BTS and to determine whether the radiofrequency radiation exposure from the selected BTS around Kaduna North Area of Kaduna State pose any health risk to people living within the study area. The Aaronia Spectran HF-4060 Analyser was chosen for this research due to its precision and portablility as compared to the aforementioned intruments in [2] and [7].

\section{MATERIALS AND METHOD}

\section{A. Study Area}

Kaduna North is one of the largest city in terms of population and land mass within Kaduna State metropolis, North-West Nigeria. Kaduna North, which is geographically located within $10^{\circ} 31^{\prime}$ to $10^{\circ} 32^{\prime} \mathrm{E}$ longitude and $007^{\circ} 26^{\prime}$ to $007^{\circ} 27^{\prime}$ latitude. Kaduna North shares it boundaries with Kaduna South from the North, Birnin Gwari from the South; Igabi from the West and Chikun Government Area from the East, with a population of over 550,000 in 2010 and an estimated population of over 800,000 in 2020. The incremental change in population of Kaduna North has contributed to the expansion of the built areas and the number of BTS within the city.

\section{B. Experimental Procedure}

The materials that were used in this study include: Aaronia Spectran HF-4060 Analyzer (Aaronia AG-Germany), Global Positioning System (GPS), Measuring tape, Inverter (Rated 1.5KWVA), Connecting wires and Battery $(12 \mathrm{~V})$. The equipments are connected in series and it was ensured that every device was properly connected before the RF analyzer was turned on. The first reading was taken at $20 \mathrm{~m}$ for the power density (in $\mu \mathrm{Wm}^{-2}$ ), and the Mean electric field strength (in $\mathrm{Vm}^{-1}$ ) was computed. The same procedure was repeated at a distance of $40 \mathrm{~m}, 60 \mathrm{~m}, 80 \mathrm{~m}$ and $100 \mathrm{~m}$ using the measuring tape to measure the distances respectively. The GPS was used to observe the latitude and longitude of that particular area were the BTS is located.

\section{Permissible Exposure Guidelines Values}

The permissible exposure limit for occupant living around the area where the BTS is mounted is $50 \mathrm{Wm}^{-2}$ for occupational exposure and $10 \mathrm{Wm}^{-2}$ as shown in Table I. If the exposure limits exceed $50 \mathrm{Wm}^{-2}$ and $10 \mathrm{Wm}^{-2}$ for both Occupational exposure and General public exposure, then people around the area are in danger of health risk. The radiation emitted from the BTS causes diseases like: cancer, weight loss, skin irritation, poor eye sight and chronic fatigue due to continuous bombardment of electromagnetic radiation from the BTS to its surroundings [8]. In this study the exposure limit in Table I was adopted $[9,10]$.

Table I Permissible Exposure Limits

\begin{tabular}{cc}
\hline Exposure characteristics & $\begin{array}{c}\text { Power density } \\
\left(\mathrm{Wm}^{-2}\right)\end{array}$ \\
\hline Occupational exposure & 50 \\
General public exposure & 10 \\
\hline
\end{tabular}

\section{RESUlTS AND DISCUSSIONS}

\section{A. Data Collections}

The various data collections within around Kaduna North Area of Kaduna are shown in Table II indicates the power density increases by square of radial distance $\left(\mathrm{P}_{\mathrm{A}} / 4 \pi \mathrm{R}_{2}\right)$ farther away from $20 \mathrm{~m}$ to $100 \mathrm{~m}$.

\section{Table II Power Density of all BTS}

\begin{tabular}{ccccccccccc}
\hline $\begin{array}{c}\text { Distance } \\
\text { (m) }\end{array}$ & \multicolumn{10}{c}{ Power Density $\left(\mu \mathrm{Mm}^{-2}\right)$} \\
\cline { 2 - 11 } & BTS1 & BTS2 & BTS3 & BTS4 & BTS5 & BTS6 & BTS7 & BTS8 & BTS9 & BTS10 \\
\hline 20.00 & 68.07 & 20.80 & 25.10 & 118.90 & 49.34 & 111.60 & 323.14 & 22.13 & 61.46 & 211.71 \\
40.00 & 40.98 & 35.76 & 46.76 & 88.45 & 38.87 & 174.90 & 168.43 & 12.17 & 108.51 & 232.54 \\
60.00 & 30.68 & 44.96 & 75.07 & 11.64 & 24.63 & 182.60 & 134.24 & 17.71 & 153.04 & 322.10 \\
80.00 & 23.67 & 19.65 & 54.56 & 48.67 & 28.98 & 199.94 & 219.95 & 3.41 & 29.81 & 429.77 \\
100.00 & 11.60 & 3.56 & 24.81 & 60.86 & 30.28 & 203.44 & 173.40 & 3.03 & 9.04 & 562.66
\end{tabular}

\section{B. Mean power Density}

Mean power density of all the collected BTS is computed as shown in Table III below. 
Table III Mean Power Density of all BTS

\begin{tabular}{ccc}
\hline $\begin{array}{c}\text { Distance } \\
(\mathrm{m})\end{array}$ & $\begin{array}{c}\text { Mean power } \\
\text { density }\left(\mu \mathrm{Wm}^{-2}\right)\end{array}$ & $\begin{array}{c}\text { Percentage } \\
\text { Contribution }(\%)\end{array}$ \\
\hline 20.00 & 101.23 & 19.86 \\
40.00 & 94.74 & 18.59 \\
60.00 & 99.67 & 19.56 \\
80.00 & 105.78 & 20.75 \\
100.00 & 108.27 & 21.24 \\
\hline
\end{tabular}

The highest and lowest values obtained for the measured mean power density were $108.27 \mu \mathrm{Wm}^{-2}$ and $94.74 \mu \mathrm{Wm}^{-2}$ from a distance of $100 \mathrm{~m}$ and $40 \mathrm{~m}$ as shown in Table III. The power density increases by square of radial distance $\left(\mathrm{P}_{\mathrm{A}} / 4 \pi \mathrm{R}^{2}\right)$ farther away from the reference $\mathrm{BS}$ as indicated in the Table III.

\section{Mean Electric Field Strength}

Mean electric field strength combined of all BTSs was also computed as depicted in Table IV using (1).

$$
\mathrm{E}\left(\mathrm{Vm}^{-1}\right)=\sqrt{(S)\left(W m^{-2}\right) \times(377)}
$$

Where $\mathrm{E}\left(\mathrm{Vm}^{-1}\right)=$ Electric Field Strength, $\mathrm{S}\left(\mathrm{Wm}^{-2}\right)=$ Exposure limits.

Table IV Mean Electric Field Strength of all BTS.

\begin{tabular}{cc}
\hline Distance $(\mathrm{m})$ & Mean electric field strength $\left(\mathrm{Vm}^{-1}\right)$ \\
\hline 20.00 & 195.36 \\
40.00 & 188.99 \\
60.00 & 193.84 \\
80.00 & 199.70 \\
100.00 & 202.03
\end{tabular}

Table IV above, show the highest mean electric field strength was $202.03\left(\mathrm{Vm}^{-1}\right)$ at $100 \mathrm{~m}$ while the lowest mean electric field strength was $188.99\left(\mathrm{Vm}^{-1}\right)$ at $40 \mathrm{~m}$. The electric field strength shows an increase farther away from the reference BTS except at $40 \mathrm{~m}$ due to immobile structure and mechanical disturbances.

Fig. 1 shows that the mean power density as computed in Table III, increases by square of radial distance $\left(\mathrm{P}_{\mathrm{A}} / 4 \pi \mathrm{R}^{2}\right)$ farther away from the reference BTS except at $40 \mathrm{~m}$ due to immobile structure and mechanical disturbances. The mean electric field strength shows an increase farther away from the reference BTS as indicated in the Table IV. As the distance increases the mean electric field strength also increases. At $40 \mathrm{~m}$, the mean electric field strength decrease due to immobile structures and mechanical disturbances as shown in Fig. 2. Equally, Fig. 3 shows the various percentage of emission as indicated in Table III.

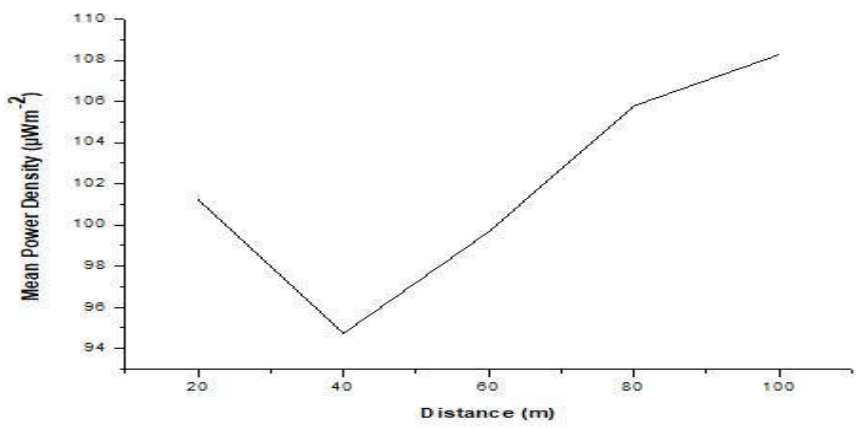

Fig. 1 Showing Graph of Mean Power Density versus Distance

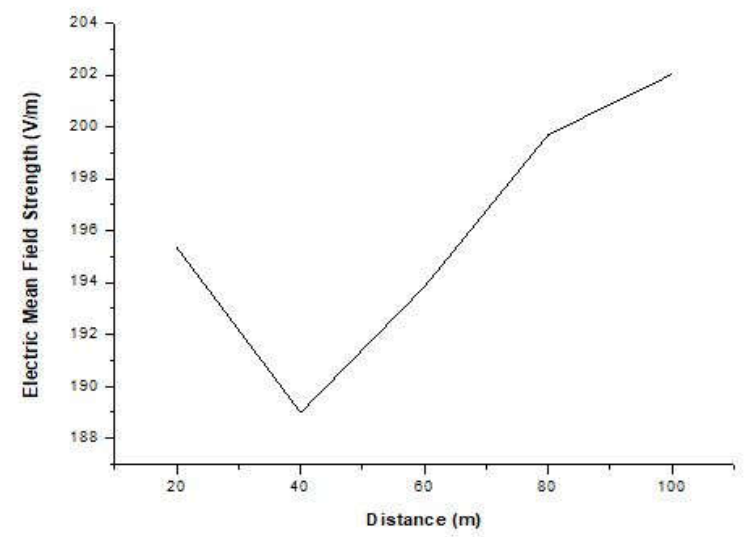

Fig. 2 Showing Graph of Mean Electric Field Strength versus Distance

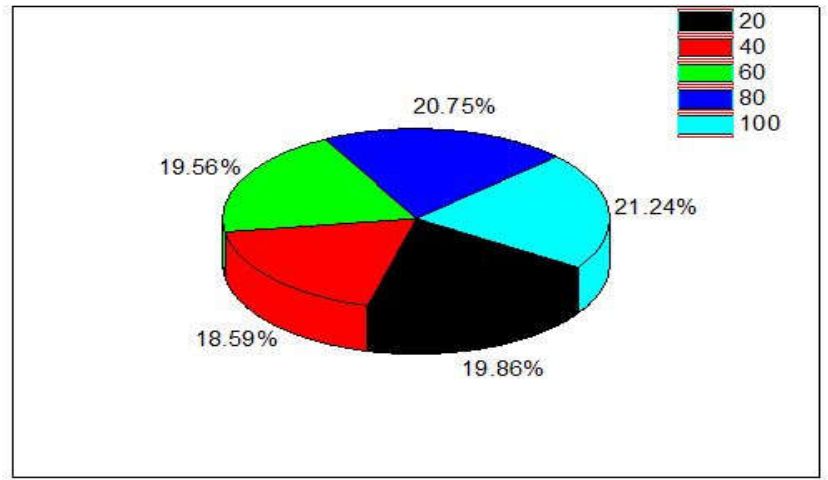

Fig. 3 Showing Percentage Contribution of Mean Power Density of all BTS.

\section{COnclusions}

The mean power density at the selected telecommunication BTS around Kaduna North Area of 
Kaduna State were successfully measured and readings where recorded accordingly. The mean power density over all locations was evaluated to be $509.69 \mu \mathrm{wm}^{-2}$ and the maximum power density as well as the average value is by far less than the allow exposure permissible limits. The distance from the BTS is a major factor that determines the level of radiation absorbed by the human body, the closer the distance of human beings to the BTS the higher the rate of radiation absorbed by the body and the higher the health risk.

The results obtained indicates that the radiofrequency radiation exposure from the selected BTS around Kaduna North Area of Kaduna State poses no health risk as such people living around the telecommunication masts are safe.

\section{REFERENCES}

[1] B. O. Ayinmode and I. P. Farai, "Measurement and Method in Radiofrequency Radiation Exposure Assessments", The Pacific J. Sci. \& Tech., vol. 14, no. 2, pp. 110-118, 2013.

[2] I. Magaji, K. A. Ibrahim and I. Ahmed. "Survey and Assessment of Radiation Levels Associated with Mobile and Wireless Telecommunication Mast in Residential and Office Areas within Kaduna Metropolis." FUDMA J of Sci. (FJS), vol. 3, no. 3, pp. $341-347,2019$.

[3] D. Musa, A. Y. Abbas, F. Y. Umar and B. M. Adeleye. "Assessment of Spatial Distribution of Telecommunication Base Stations and Compliance Level of the Operators to the Regulations in Federal Capital City Abuja, Nigeria", J of Sust. Dev. in Afric, vol. 18, no. 3, 2016.

[4] Nigerian Communication Commission, NCC Industry Statistics: Industry Report. NCC Publication, 2020.

[5] A. O. Akindele and O. A. Tosin. "Perceived Housing Satisfaction in Public Estates Box Oshogbo Nigeria." J of Geo. \& Reg. Planning, vol. 7, no. 9, pp. 185-191, 2014.

[6] A. Akintowa, A. A. Busari, O. Awodele and S. O. Olayemi. "The Hazard of Non-Ionizing Radiation of Telecommunication Mast in an Urban Area of Lagos Nigeria", African J of Biomedical Research, vol. 12, no. 1, 2009.

[7] H. Ali and O. Go, "A Survey of Radiation Levels Associated with Mobile and Wireless Communication Technology Masts in Public Areas in Kaduna Metropolis", Int. J of Emerg. Eng. Res. and Tech., vol. 3, no. 11, pp. $171-121,2015$.

[8] F. A. Anita and O. U. Fredrick. "Assessment of Radiofrequency Radiation Levels of Mobile Phones and Evaluation of Specific Absorption Rate to Tissues of Human Head Layers", FUW Trends in Sci. \& Tech. J., vol. 4, no. 3, pp. 643-650, 2019.
[9] I. A. Bello, A. Sa'id, M. A. Vatsa, A. Asuku and N. Kure, "Power Density Measurements for Associated Risk of Radio Frequency Radiation in Relation to Safety Limits for Human Exposure to EMF's in Zaria, Nigeria", Kada J of Phy, vol. 2, no. 2, pp. 5963, 2020.

[10] International Commission on Non-ionizing Radiation Protection (ICNIRP). "Guidelines for limiting Exposure to Time-Varying Electric, Magnetic, and Electromagnetic fields (up to 300 GHz).” Health Phy, vol., 74, pp. 494-522, 1988. 